\title{
No free lunch in orthopedics
}

\author{
Benjamin A. Goldberg ${ }^{1}$ - Marius M. Scarlat ${ }^{2}$
}

Published online: 11 September 2017

(C) SICOT aisbl 2017

"There is no such thing as a free lunch" is an adage that referred to the effect of patrons of a nineteenth century strategy used by liquor establishments in the United States to entice consumers to enter and have lunch without cost. However, customers would presumably on average purchase alcohol in sufficient quantity that it would be profitable for the liquor establishment despite serving food "for free".

Today, the term refers to the observation that one usually cannot get something of value without either an obvious significant financial or indirect cost or a non-obvious cost. One example of a non-obvious cost is a potential unrealized negative effect. In other words, one cannot get something for nothing. Charity is exempt from this basic exchange algorithm as charity is based on moral principles such as giving away for a better moral image or for a place in heaven. (-)

In mathematical folklore, the "no free lunch" theorem of David Wolpert and William Macready is published in 1997 [1]. In computer programming, no free lunch has been demonstrated in theory that if something "performs well on a certain class of problems then it necessarily pays for that with degraded performance on the set of all remaining problems."

Orthopedic surgeons as well as other medical professionals have been blinded by the lure and possibility of a "free lunch" over the last several decades. The goal of orthopedic surgery should be to restore function, improve motion, minimize pain,

Marius M. Scarlat

mscarlat@gmail.com

Benjamin A. Goldberg

bgoldber@uic.edu

1 University of Illinois, Chicago, IL, USA

2 Clinique St Michel, Toulon, France or prevent a negative outcome such as loss of life or limb. For example, a patient with an ACL deficient knee may experience instability or diminished function upon sustaining a knee ligament injury. Some patients undergoing ACL reconstruction surgery may experience an obvious complication or suboptimal outcome including infection, graft failure, or failure to return to their prior level of sport. However, even if one excludes these early obvious negative outcomes, long-term consequences that may not be obvious early on in the development of the procedure may include a higher rate of arthrosis in the surgically reconstructed knee than if treated without surgery. Problems with implants used in this type of surgery were also described [2]. Commonly, there are technological "advances" of a procedure or implant where some known challenge or shortcoming of surgical reconstruction is "improved". For example, the traditional femoral stem of a hip arthroplasty that has a fixed neck angle and anteversion relative to the stem cross-sectional geometry cannot perfectly anatomically reproduce normal lateral offset, limb length, and version in most patients. Traditionally, compromises were made intraoperatively with endoprosthetics to obtain adequate stability and range of motion and limb length. Recently, manufacturers "improved" design by allowing a new modular junction between the stem and neck to try to improve anatomical reconstruction and minimize implant inventory. The manufactures were trying to "have it all" in terms of benefitting patients and additionally likely improving profitability. This advance allowed intraoperative alteration and pseudocustomization of an implant to try to more naturally reproduce anatomy. Even if one ignored the obvious economic downside of increased cost of such implants to a health care system (there is already a significant cost to this "meal"), short and mid-term studies have demonstrated a significantly higher failure rate than the prior generation prosthetics without such modularity due to corrosion and metallurgical failure. This 
anticipated "improvement" in patient outcomes and corporate profitability did not materialize because it was not anticipated that the non-obvious (at the time) improvement may be a design or other flaw that could lead to costly litigation and revision surgery. [3]. Other cases were related to a specific implant design either in hip or shoulder, they are recognized in the literature and the indications should be made with caution with a clear logic of choice that include the possibilities of failure [4-7]

Other "solutions" include trying to minimize a problem (polyethylene wear) with metal-on-metal articulations, which caused potentially a worse problem with metal ion disease. Shoulder surgeons have seen surgical induced chondromalacia from implants or chemical/medications placed in the shoulder or thermal devices [8], failures from partial resurfacing arthroplasties [4], knee surgeons have seen increased rates of revision of unicompartmental arthroplasty [9], hand surgeons have seen silicone failures [10].

Until recently, ankle arthroplasty was fraught with high rates of loosening and revision [11]. Spine surgery has seen tremendous advances in techniques in implants as well as cost, but proven improvement in patient outcomes has not been well documented $[12,13]$.

Orthopedic surgeons have also literally accepted free lunches (and dinners and other gifts) from manufacturers who have a goal of being profitable. Clearly there is a direct cost to a manufacturer to give away lunch or dinner or other gifts. Manufacturers have been able to recoup that cost (and more) via increased volume of prosthetics implanted or via the introduction and adoption of a newer, more expensive, and more profitable implant. Many of these new techniques have not been shown to have better outcomes than prior techniques. Furthermore, many newer implants have not been shown to be superior in terms of longevity or outcomes compared to prior outcomes, but are typically more expensive. Personalized implants and single use tools are more expensive and large volume studies should clearly answer in the future if the investment will return better health or quality of living as compared to the traditional tools and implants $[14,15]$

When Ponzi type "investments" are uncovered before complete collapse of the scheme, it is typically because an investigator noting that the investment "sounds too good to be true" relative to the potential risk of loss of the investment. Orthopedic surgeons need to have the same vigilance with emerging techniques and technologies to protect our patients and society.

\section{References}

1. Wolpert DH, Macready WG (1997) No free lunch theorems for optimization. IEEE Trans Evol Comput 1:67
2. Virk SS, Kocher MS (2011) Adoption of new technology in sports medicine: case studies of the gore-Tex prosthetic ligament and of thermal capsulorrhaphy. Arthroscopy 27(1):113-121. https://doi. org/10.1016/j.arthro.2010.06.001

3. Colas S, Allalou A, Poichotte A, Piriou P, Dray-Spira R, Zureik M (2017) Exchangeable femoral neck (dualmodular) THA prostheses have poorer survivorship than other designs: a Nationwide cohort of 324,108 patients. Clin Orthop Relat Res 475(8):2046-2059. https://doi.org/10. 1007/s11999-017-5260-6

4. Delaney RA, Freehill MT, Higgins LD, Warner JJ (2014) Durability of partial humeral head resurfacing. J Shoulder Elb Surg 23(1):e14 e22. https://doi.org/10.1016/j.jse.2013.05.001

5. Elmallah RK, Cherian JJ, Meneghini RM, Hozack WJ, Westrich GH, Mont MA (2016) How to approach a recalled dual modular hip implant: an update. J Arthroplast 31(11):2646-2652. https://doi. org/10.1016/j.arth.2016.06.059

6. Fitch DA, Ancarani C, Bordini B (2015) Long-term survivorship and complication rate comparison of a cementless modular stem and cementless fixed neck stems for primary total hip replacement. Int Orthop 39(9):1827-1832. https://doi.org/10.1007/s00264-0152894-4

7. Hernigou P, Dubory A, Potage D, Roubineau F, Flouzat Lachaniette CH (2017) Dual-mobility arthroplasty failure: a rationale review of causes and technical considerations for revision. Int Orthop 41(3):481-490. https://doi.org/10.1007/ s00264-016-3328-7

8. Serrato JA Jr, Fleckenstein CM, Hasan SS (2011) Glenohumeral chondrolysis associated with use of an intraarticular pain pump delivering local anesthetics following manipulation under anesthesia: a report of four cases. J Bone Joint Surg Am 93(17):e99(1-8). https://doi.org/10. 2106/JBJS.J.01604

9. Citak M, Dersch K, Kamath AF, Haasper C, Gehrke T, Kendoff D (2014) Common causes of failed unicompartmental knee arthroplasty: a single-centre analysis of four hundred and seventy one cases. Int Orthop 38(5):961-965. https://doi.org/10.1007/ s00264-013-2263-0

10. Wanivenhaus A (2006) Implants in the hand.(in German). Radiologe 2006;46(9):753-756 758-9

11. Noelle S, Egidy CC, Cross MB, Gebauer M, Klauser W (2013) Complication rates after total ankle arthroplasty in one hundred consecutive prostheses. Int Orthop 37(9):1789-1794. https://doi. org/10.1007/s00264-013-1971-9

12. Choi E, Yazsay B, Mundis G, Hosseini P, Pawelek J, Alanay A, Berk H, Cheung K, Demirkiran G, Ferguson J, Greggi T, Helenius I, La Rosa G, Senkoylu A, Akbarnia BA (2016) Implant complications after magnetically controlled growing rods for early onset scoliosis: a multicenter retrospective review. J Pediatr Orthop

13. Schiffer G, Goldmann S, Faymonville C, Müller L, Stein G (2016) 3D-Navigated implantation of pedicle screws in the cervical spine experience and analysis of complications. Z Orthop Unfall 2016;154(5):483-487 In German

14. Thienpont E, Bellemans J, Delport H, Van Overschelde P, Stuyts B, Brabants K, Victor J (2013) Patient-specific instruments: industry's innovation with a surgeon's interest. Knee Surg Sports Traumatol Arthrosc 21(10):2227-2233. https://doi.org/10.1007/s00167-0132626-5

15. Predescu V, Prescura C, Olaru R, Savin L, Botez P, Deleanu B (2017) Patient specific instrumentation versus conventional knee arthroplasty: comparative study. Int Orthop 41(7):1361-1367. https://doi.org/10.1007/s00264-016-3356-3 